\title{
Single approach to double-channel core decompression and bone grafting with structural bone support for treating osteonecrosis of the femoral head in different stages
}

\author{
Ju'an Yue ${ }^{\dagger}$ Xiaozhong Guo*+(D, Randong Wang, Bing Li, Qiang Sun, Wangyan Liu, Jiao Chen and Yingnan Li
}

\begin{abstract}
Background: We created a novel method - single approach to double-channel core decompression and bone grafting with structural bone support (SDBS) - to treat early-stage osteonecrosis of the femoral head (ONFH) by improving the Phemister technique. This study aimed to evaluate the results of SDBS for early-stage ONFH.

Methods: Altogether, 53 patients (73 hips) were treated using SDBS during 2016-2018. Bilateral (20 patients) and unilateral (33 patients $=18$ left hips, 15 right hips) ONFH was diagnosed. According to the Association Research Circulation Osseous classification stages, the femoral heads were staged as IIB $(n=15)$, IIC $(n=19)$, IIIA $(n=34)$, IIIB $(n=4)$, and IIIC $(n=1)$. The Harris hip score was used to evaluate the hips' clinical function, computed tomography to evaluate subchondral fractures, and plain radiography to assess the extent of femoral head collapse.

Results: The average follow-up was $20.71 \pm 6.65$ months (6-36 months). At the patients' last follow-up, 4 hips were found to require arthroplasty. Thus, the overall femoral head survival rate was $94.52 \%$ (69/73). Also, the overall Harris score $(84.44 \pm 14.57)$ was significantly higher than that preoperatively $(77.67 \pm 14.37)(P=0.000)$. The combined excellent and good rate $(76.71 \%)$ was significantly higher than that preoperatively $(38.36 \%)(P=0.000)$. Imaging showed that 16 femoral heads had some ONFH progression. The average length of stay was $6.15 \pm 0.86$ days. The average incision measured $2.69 \pm 0.30 \mathrm{~cm}$. Intraoperative blood loss was $61.20 \pm 4.81 \mathrm{ml}$. There were no complications during or after the operation.
\end{abstract}

Conclusion: SDBS is an effective method for treating early-stage ONFH. It is a hip-preserving surgical approach to slow/prevent ONFH progression.

Keywords: Single approach, Double-channel, Core decompression, Bone grafting

\footnotetext{
* Correspondence: guoxiaozhong361@sina.com

†Ju'an Yue and Xiaozhong Guo contributed equally to this work. Department of Joint Surgery, Aviation General Hospital, Courtyard 3, Anwai Beiyuan, Chaoyang District, Beijing, China
}

(c) The Author(s). 2020 Open Access This article is licensed under a Creative Commons Attribution 4.0 International License, which permits use, sharing, adaptation, distribution and reproduction in any medium or format, as long as you give appropriate credit to the original author(s) and the source, provide a link to the Creative Commons licence, and indicate if changes were made. The images or other third party material in this article are included in the article's Creative Commons licence, unless indicated otherwise in a credit line to the material. If material is not included in the article's Creative Commons licence and your intended use is not permitted by statutory regulation or exceeds the permitted use, you will need to obtain permission directly from the copyright holder. To view a copy of this licence, visit http://creativecommons.org/licenses/by/4.0/ The Creative Commons Public Domain Dedication waiver (http://creativecommons.org/publicdomain/zero/1.0/) applies to the data made available in this article, unless otherwise stated in a credit line to the data. 


\section{Introduction}

Osteonecrosis of the femoral head (ONFH) is a progressive, destructive disease of the hip joint caused by factors such as hormones, alcohol abuse, and trauma [1]. These factors can directly or indirectly destroy the blood circulation of the femoral head, in which case the survival of bone cells and bone marrow tissue may be affected [2, 3]. If, during this period, there is no effective treatment applied, most patients experience progression to femoral head collapse and hip osteoarthritis, resulting in the need for hip arthroplasty [4].

ONFH often occurs in young patients, and total hip replacement is not an ideal choice for them because they will face the risk of revision in the future. Therefore, an early intervention is very important for them $[5,6]$. There are many surgical procedures used to preserve the femoral head, including core decompression, vascularized and non-vascularized bone grafts, various types of osteotomy, and a porous tantalum implant [7, 8]. In 1949, Phemister introduced a new, non-vascularized bone-grafting technique that now carries his name [9]. That procedure is as follows: First, a cone of the bone about $8-10 \mathrm{~mm}$ in diameter is removed from the femoral head and neck via a lateral approach to the proximal femur. The necrotic bone in the femoral head is then debrided, and a strut consisting of a cortical graft is inserted to provide subchondral support to the femoral head.

We improved this Phemister technique by using a drill (diameter $10 \mathrm{~mm}$ ) to decompress the necrotic area via double channels and then remove part of the necrotic bone through the channels. The two channels are then filled with fresh-frozen allograft and demineralized bone matrix, after which a nano-hydroxyapatite/polyamide-66 support rod is inserted into the outer top hole to provide subchondral support. We called this procedure the "single approach to double-channel core decompression and bone grafting with structural bone support (SDBS)." In this study, we reported the short-term efficacy of treating ONFH with this new procedure.

\section{Materials and methods}

The Ethics Committee of our hospital approved this study. All patients agreed to participate in it.

Altogether, 53 patients ( 8 female, 45 male; mean age $38.43 \pm 10.48$ years, range $16-58$ years; mean body mass index $24.60 \pm 3.14 \mathrm{~kg} / \mathrm{m}^{2}$, range $16.98-33.22 \mathrm{~kg} / \mathrm{m}^{2}$ at the time of surgery) were treated with SDBS between October 2016 and September 2018 for ONFH. The ONFH was bilateral in 20 patients and unilateral in 33 patients (18 in the left hip, 15 in the right hip). The causes of ONFH included corticosteroids in 22 patients (32 hips), alcohol abuse in 17 patients (23 hips), and trauma in 6 patients (6 hips). It was idiopathic in 8 patients (12 hips). The Association Research Circulation
Osseous (ARCO) classification was the basis on which we diagnosed, analyzed, and classified ONFH [1]. The femoral heads were staged as IIB $(n=15)$, IIC $(n=19)$, IIIA $(n=34)$, IIIB $(n=4)$, and IIIC $(n=1)$.

\section{Primary materials}

The primary materials included nano-hydroxyapatite/polyamide-66 support rods (Sichuan National Nanotechnology Co., Ltd., Chengdu, China) (Fig. 1), fresh-frozen allograft (FFA) (Shanxi AoRui Biological Material Co., Ltd, Taiyuan, China), and demineralized bone matrix (DBM) (Wright Medical Technology, Inc., Memphis, TN, USA).

\section{Surgical technique}

All operations were performed by the same senior doctor in the Orthopedic Department of Aviation General Hospital. First, 10 mg FFA mixed with 1 cc DBM was prepared to fill the double channels. We planned the direction of these double channels on plain radiographs (Fig. 2, panel 1). All patients underwent epidural anesthesia, and after it was deemed satisfactory, the patient was fixed in the traction bed (Fig. 2, panel 2). A Kirschner wire was then placed on the body surface to locate the necrotic area and direction of the wire (Fig. 2, panel 3). Fluoroscopy was used to evaluate the direction of the guide wire (Fig. 2, panel 4), which was then marked on the body surface (Fig. 2 , panel 5). Routine surgical areas were disinfected, and sterile towels were applied. After selecting the optimal entrance point, the first guide wire was introduced below and inside the necrotic area (Fig. 2, panels 6 and 7), and a $2-\mathrm{cm}$ skin incision was made at the optimal entrance point. Then, a 10-mm cannulized drill bit was used to extend the diameter along the guide wire up to $3 \mathrm{~mm}$ below the cartilage (Fig. 2, panels 8 and 9). FFA particles (7.5 $\mathrm{mg}$ ) were transplanted into the channel from the necrotic area to the normal area (Fig. 2, panel 10). The second guide wire was then introduced into the outer, top necrotic area from the same entrance point (Fig. 2, panels 11 and 12), and a 10-mm cannulized drill bit was used to extend the diameter along the guide wire up to $3 \mathrm{~mm}$ below the cartilage (Fig. 2, panels 13 and 14). FFA particles (2.5 $\mathrm{mg}$ ) were transplanted into the top of the channel (Fig. 2, panel 15), and a measuring stick was used to determine the length of the second channel (Fig. 2, panel 16). After reaming the proximal femur (Fig. 2, panel 17), a suitable support rod was selected to be inserted into the second channel (Fig. 2, panel 18). The area was then irrigated and the incision sutured. The postoperative radiograph is shown in Fig. 2 (panel 19), as is a photograph of the actual product (panel 20).

\section{Postoperative treatment}

Postoperatively, the patients were given celecoxib to relieve pain and enoxaparine 4000 aXa IU for thrombosis 


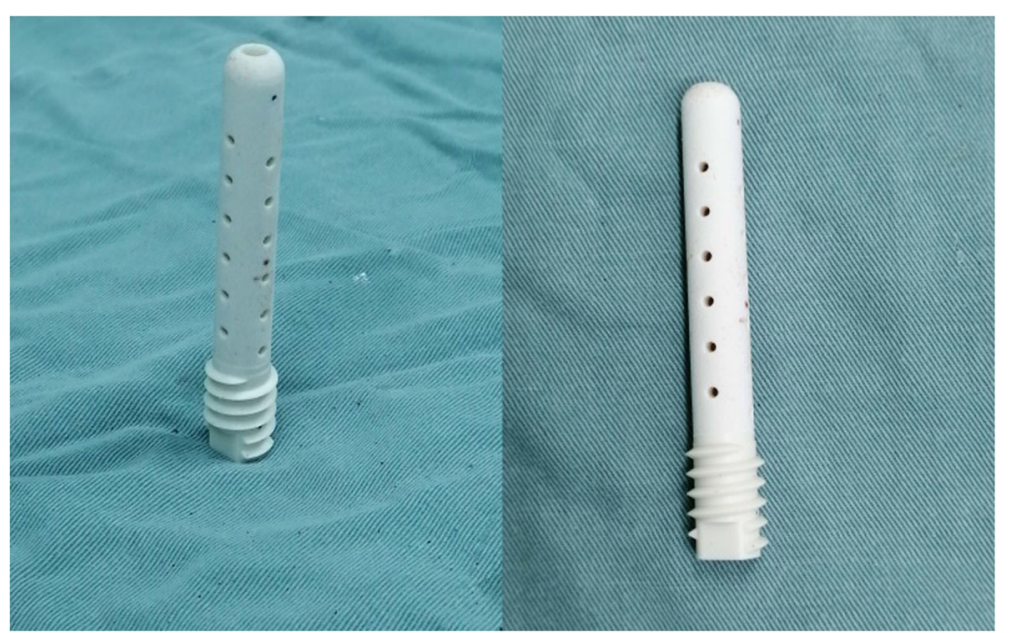

Fig. 1 The nano-hydroxyapatite/polyamide-66 (n-HA/PA66) support rod. It is a hollow cylinder (10-mm outer diameter, 4-mm inner diameter) with several holes around the outside

prophylaxis for 7 days after surgery. No other medicine was prescribed. Each patient then participated in a strict rehabilitation and training program. One day after the operation, the patients were advised to start walking with protected weight bearing, using two crutches, and to continue this regimen for the next 6 months. Then, from 7 to 12 months, the patients were advised to begin to discard the use of the crutches and to practice walking with full weight bearing. Thus, by 1 year postoperatively, all patients had completely abandoned the need for crutches.

\section{Efficacy assessment}

All patients underwent follow-up evaluations at 6 and 12 months after surgery during the first year and yearly thereafter. The endpoint of the follow-up was determined by the time that elapsed until the conversion to THA. The Harris hip score (HHS) was used to evaluate the hips' clinical function. HHS criteria are as follows: excellent (HHS $\geq 90$ ), good ( $\leq 89$ to $\geq 80$ ), fair ( $\leq 79$ to $\geq 70$ ), and poor $(<70)$. Anteroposterior and lateral plain radiography and computed tomography were performed at each follow-up. Computed tomography was used to evaluate subchondral fractures and radiography to assess the extent of the collapse of the femoral head. Radiographic progression of femoral head collapse was evaluated in consideration of the ARCO classification. The collapse depth of the femoral head was measured using a picture archiving and communication system (PACS, version 11.0) [10]. Two orthopedic specialists were responsible for evaluating all radiographs independently.

Other efficacy assessments included the operation time, intraoperative blood loss, length of stay, and postoperative complications. If the patient underwent total hip arthroplasty (THA) after SDBS-regardless of the cause-it was considered a failed result.

\section{Statistical analysis}

All statistical analyses were completed using SPSS version 22.0 (IBM Corp; Armonk, NY, USA). Data are expressed as means \pm standard deviations. Comparisons of the hip joints before and after surgery were performed using a paired $t$ test to calculate the HHSs prior to surgery and at the last follow-up. Rate comparisons were performed using the $\chi^{2}$ test. The life table method was used to estimate the survival rate. $P<0.05$ was considered to indicate statistical significance.

\section{Results}

All patients were enrolled in the study. The average duration of the follow-up was $20.71 \pm 6.65$ months (range 6-36 months). At the last follow-up, THA was found to be needed for 4 hips, making the survival rate of the femoral head 94.52\% (69/72). Details of the four failed hips after undergoing SDBS are shown in Table 1. The estimate of the success rate is shown in Fig. 3.

At the last follow-up, the HHS (84.44 \pm 14.57$)$ was significantly higher than that before surgery $(77.67 \pm 14.37)$ $(P=0.000)$. Preoperatively, 19 hips were evaluated as excellent, 9 as good, 22 as fair, and 23 as poor. At the last follow-up, the efficacy of SDBS was excellent, good, fair, or poor in $34,22,7$, and 10 hips, respectively. Preoperatively and at the last follow-up, the number of hip joints at different stages of clinical efficacy is shown in Fig. 4. The combined excellent and good rate at the last followup $(76.71 \%)$ was significantly higher than that before the SDBS operation $(38.36 \%)(P=0.000)$. The changes in clinical function are shown in Table 2. 

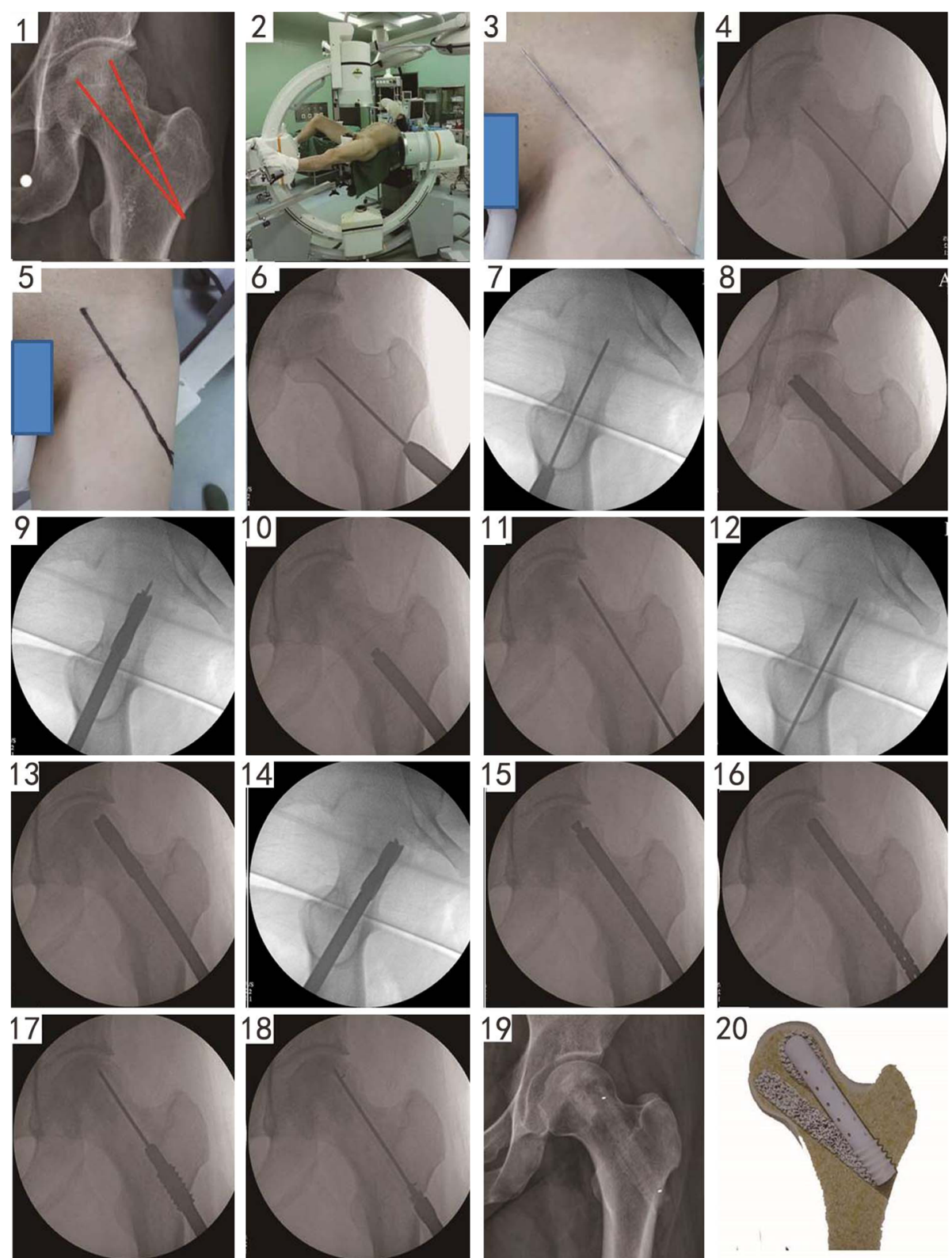

Fig. 2 Steps in the surgical procedure that are described in the text

Table 1 Characteristics of clinical failures

\begin{tabular}{|c|c|c|c|c|c|c|c|c|}
\hline$t$ & Sex & Age (years) & BMI & Left/right & Risk factors & Pre/last Harris & Pre/last ARCO & Survival time (months) \\
\hline 1 & Male & 26 & 23.4 & Left & Corticosteroids & $65.7 / 36.4$ & IIIA/IV & 14 \\
\hline 2 & Male & 37 & 22.0 & Right & Corticosteroids & $83.7 / 30.7$ & IIIA/IV & 15 \\
\hline 3 & Male & 30 & 25.6 & Right & Corticosteroids & $69 / 67$ & $\|\mathrm{II} /\| \mathrm{I}$ & 12 \\
\hline 4 & Male & 18 & 20.0 & Right & Trauma & $75.7 / 71.7$ & $\| \mathrm{IC} / \mathrm{IV}$ & 6 \\
\hline
\end{tabular}




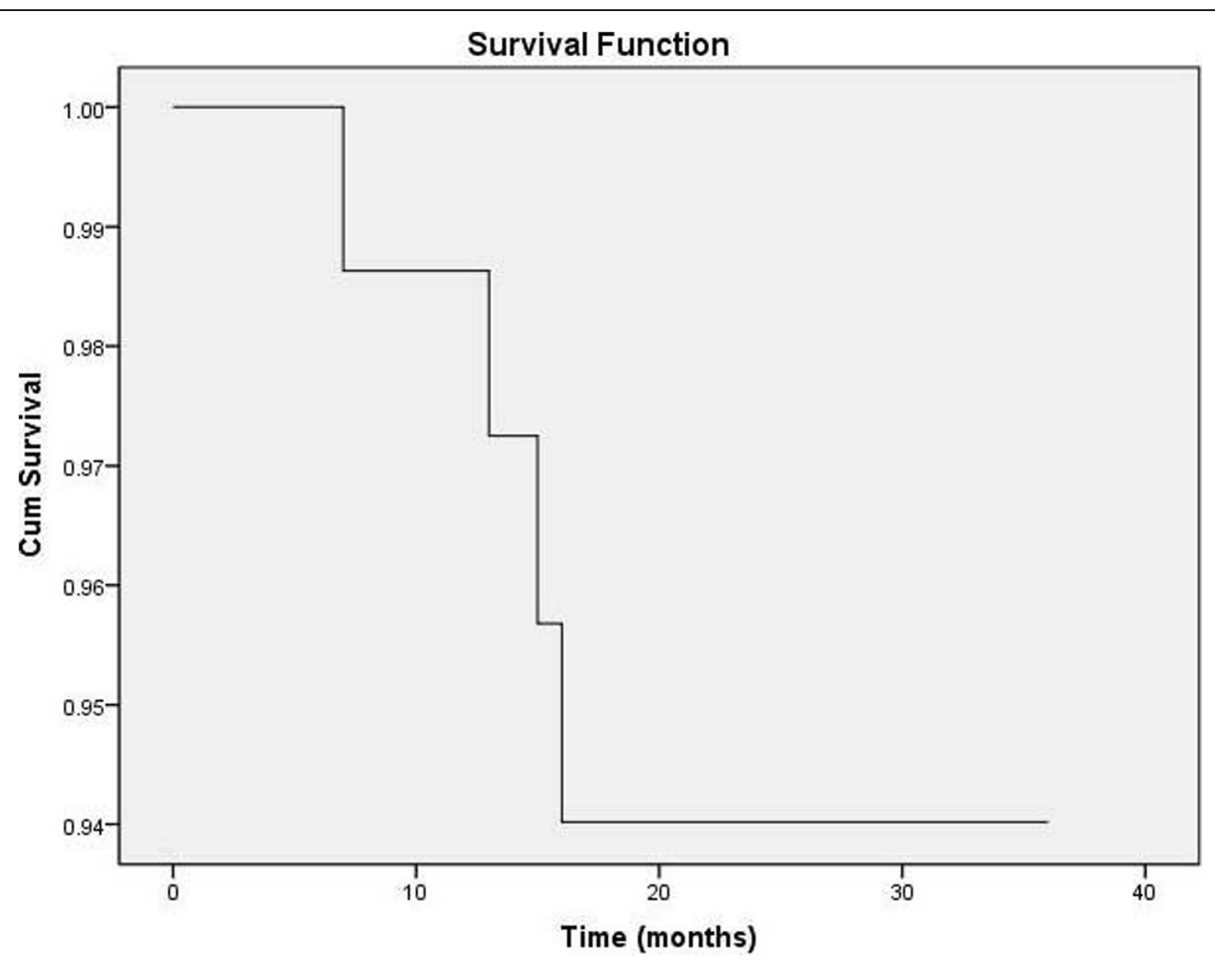

Fig. 3 Survival function of SDBS

In all, 16 femoral heads showed some progression on their imaging examination. Among the ONFH hips of ARCO stages IIB, IIC, IIIA, IIIB, and IIIC, 1 of 15 hips (6.7\%), 5 of 19 hips (26.32\%), 7 of 34 hips (20.59\%), 2 of 4 hips (50\%), and 1of 1 hip (100\%), respectively, exhibited progression of femoral head collapse on imaging examinations. Preoperatively and at the last follow-up, the number of femoral heads at different stages of ARCO is shown in Fig. 5. The extents of the progression are shown in Table 3.

The average length of stay was $6.15 \pm 0.86$ days (range $5-8$ days). The average incision measured $2.69 \pm 0.30 \mathrm{~cm}$ (range $2.0-3.5 \mathrm{~cm}$ ). Intraoperative blood loss was 61.20 $\pm 4.81 \mathrm{ml}$ (range $50-73 \mathrm{ml}$ ). No complications (e.g.,

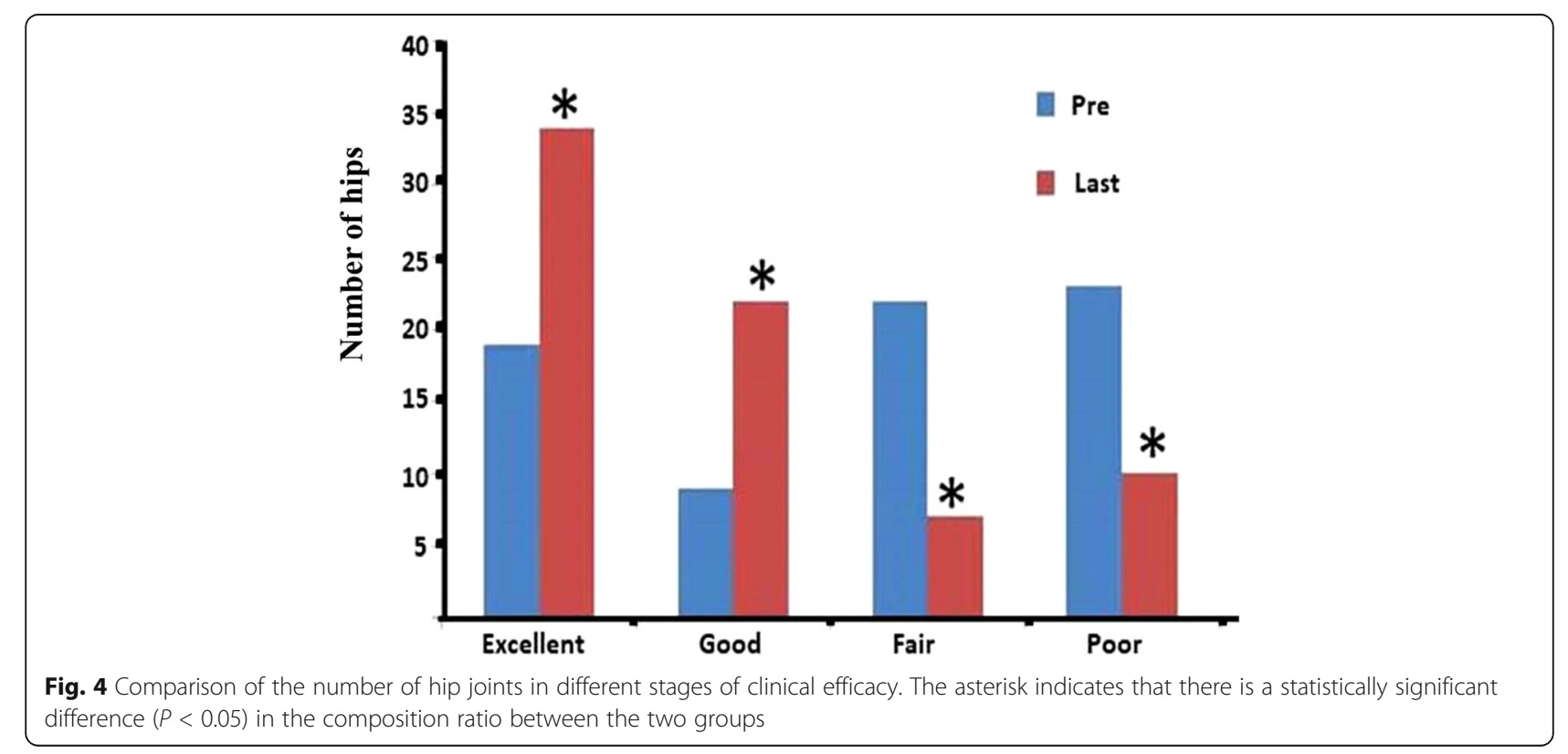


Table 2 Clinical function of the hips

\begin{tabular}{lllll}
\hline Pre-function & \multicolumn{4}{l}{ Last follow-up function } \\
\cline { 2 - 5 } & Poor $(n)$ & Fair $(n)$ & Good $(n)$ & Excellent $(n)$ \\
\hline Excellent $(n=19)$ & 2 & 1 & 6 & 10 \\
Good $(n=9)$ & 1 & - & 3 & 5 \\
Fair $(n=22)$ & 4 & 4 & 6 & 8 \\
Poor $(n=23)$ & 3 & 2 & 7 & 11 \\
Total $(n=73)$ & 10 & 7 & 22 & 34 \\
Rate $(\%)$ & $13.70 \%$ & $9.59 \%$ & $30.14 \%$ & $46.58 \%$ \\
\hline
\end{tabular}

blood vessel or nerve injury, deep vein thrombosis, wound infection, femoral fracture, rejection) occurred during or after the operation.

A typical case is shown in Fig. 6. The patient was a 55year-old woman who suffered from steroid-induced $\mathrm{ONFH}$ that was diagnosed on preoperative radiographic and magnetic resonance imaging scans (ARCO stage IIB for the left hip and IIIA for the right hip). At the 12month postoperative follow-up, the necrotic areas of the femoral heads appeared to be repaired, and the function of the hip joint had improved.

Another typical case is shown in Fig. 7. The patient was a 31-year-old man who suffered from alcoholinduced ONFH. Large areas of osteonecrosis and a meniscus sign are shown on preoperative plain radiographs. At the 8-month postoperative follow-up, the necrotic areas of the femoral heads appeared to be repaired.
Table 3 Radiological results

\begin{tabular}{lllllll}
\hline Pre-ARCO & & \multicolumn{7}{l}{ Last follow-up ARCO } \\
\cline { 3 - 8 } & IIB $(n)$ & IC $(n)$ & IIA $(n)$ & III $(n)$ & IIC $(n)$ & IV $(n)$ \\
\hline IIB $(n=15)$ & 14 & - & 1 & - & - & - \\
IIC $(n=19)$ & - & 14 & 2 & 2 & 1 & - \\
IIIA $(n=34)$ & - & - & 27 & 5 & & 2 \\
IIIB $(n=4)$ & - & & - & 2 & 2 & - \\
IIIC $(n=1)$ & - & & - & - & - & 1 \\
Total $(n=73)$ & 14 & 14 & 30 & 9 & 3 & 3 \\
Rate $(\%)$ & $19.18 \%$ & $19.18 \%$ & $41.10 \%$ & $12.33 \%$ & $4.11 \%$ & $4.11 \%$
\end{tabular}

\section{Discussion}

After being introduced in 1949, the Phemister technique became very popular during the 1950s and 1960s [11]. A fibular strut graft was first used with this technique, followed by various bone graft materials such as allografts, porous tantalum, vascularized fibula grafts, autogenous bone, and autologous stem cells. Other biomaterials, such as bone morphogenetic proteins, were also widely used in the Phemister technique to treat early-stage ONFH [11-13]. However, Hsu et al. [14] found that $32-42 \%$ of their patients failed and required a THA 13-15 months after using the Phemister technique. Keizer et al. found that the 10-year survival was $44 \%$ using the same technique [15]. Nonsurgical treatment of ONFH is accomplished using various regimens, including full weight bearing as tolerated, partial weight bearing with crutches, and non-weight bearing. No

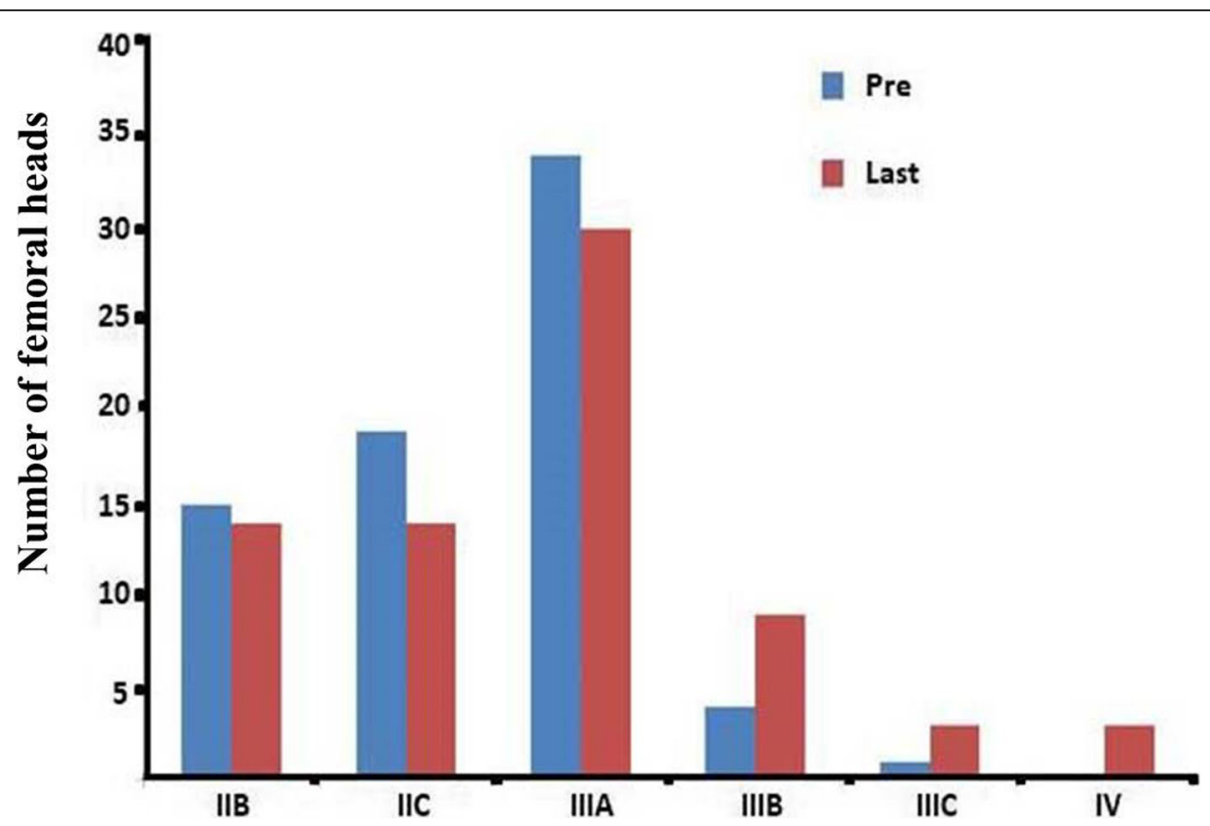

Fig. 5 Number of femoral heads at different stages of ARCO 


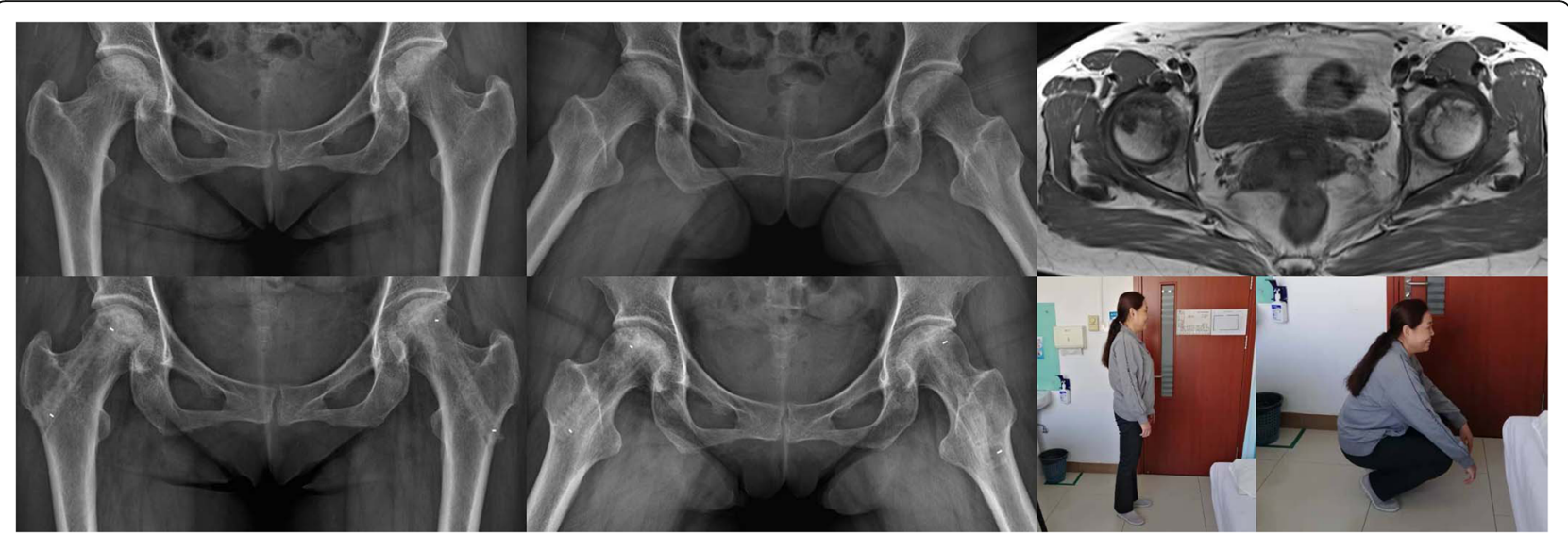

Fig. 6 Imaging data before surgery and at the last follow-up. Bottom right, last two panels show the improved patient's hip function at the last follow-up

differences have been reported in the efficacy of these nonsurgical regimens. Nevertheless, nonsurgical treatment for ONFH has been shown in multiple studies to yield extremely poor results, with an overall pooled clinical success rate of $22.7 \%$ [16].
The n-HA/PA66 support rod used in this study is composed of nanometer hydroxyapatite (HA) crystal particles evenly dispersed in PA66. HA is an active bioceramic material and the main inorganic component of human and animal bones and teeth. It acts as a scaffold

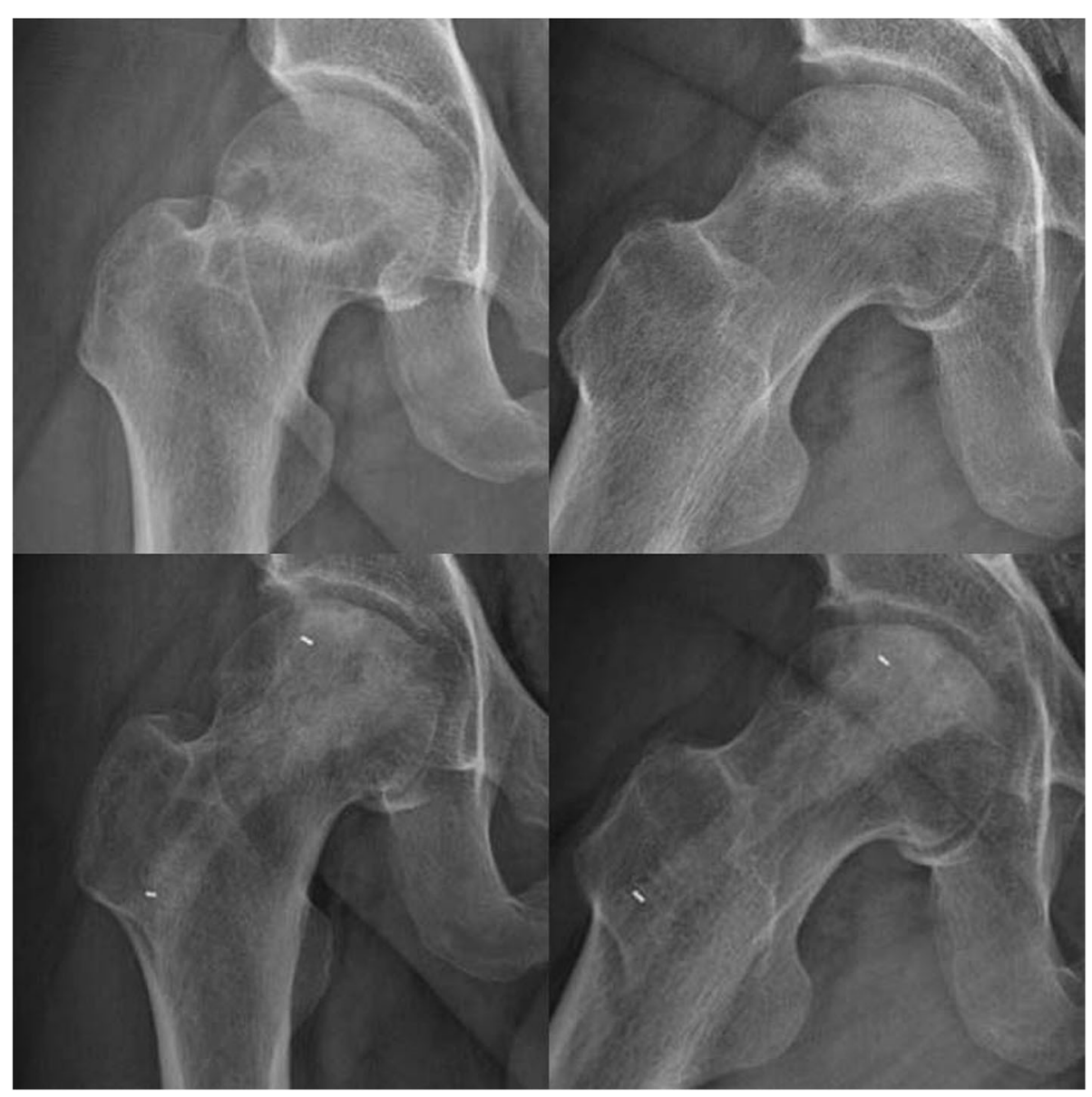

Fig. 7 Unilateral radiographs before (top) and at the last follow-up (bottom) 
for calcium salt deposition during bone metabolism and can induce new bone formation [17]. PA66 is an organic polymer material with a structure similar to that of collagen. It is easy to process and has strong plasticity [18]. Previous studies have shown that n-HA/PA66 composite biomaterials have good biocompatibility and biosafety, and they can be used to repair bone defects and promote bone growth [19, 20]. Yang et al. [21] used n-HA/PA66 to treat early-stage ONFH and achieved a good effect as it could significantly reduce pain and delay the collapse of the femoral head.

The freeze-dried allograft bone has strong bone conduction ability and is an ideal material or cell carrier for repairing bone defects [22]. In addition, it retains some bioactive bone induction components, so it also has certain bone induction ability [23, 24]. DBM offers a series of chemical methods to remove calcium and fat from the allogeneic bone, reduce immunogenicity, retain bone morphogenetic protein and other osteogenic factors, and play a role in inducing osteogenesis through these osteogenic factors.

Many studies have confirmed that an advanced ARCO stage predicted unsuccessful clinical results [25-27]. We found that, after a thorough follow-up, 7 of 34 hips (20.59\%) at ARCO stage IIIA were classified radiographically as exhibiting progression. Although the number of ARCO stage IIIB and IIIC hips is small, the imagingdetermined progress was indeed found in 50\% (2/4) and $100 \%(1 / 1)$ of cases, respectively. Therefore, we do not recommend SDBS for patients in stage IIIB or IIIC. After reviewing a decade of research on ONFH, Mont et al. [28] also concluded that the last time at which femoral head-preserving surgery can be used successfully in patients with ONFH is at the point of early collapse. We also found early during the follow-up that the clinical effect of SDBS was satisfactory for treating earlystage ONFH.

Many surgeons have used the Phemister technique to treat $\mathrm{ONFH}$ with bone grafting and structural support [25]. After a long-term observation, Guo et al. [29] found that there was a contradictory relation between the amount of bone graft and the strength of the support in a single channel. If the bone grafting and structural support were carried out for the necrotic area in the same decompressed channel, a large amount of bone grafting might affect the support strength of the material propping up the femoral head, and insufficient bone grafting might induce osteogenesis. We therefore chose to improve the Phemister technique by implanting a support rod in the outer top channel to provide strong support for the subchondral bone in the weight-bearing area that had become necrotic and to prevent the collapse of the femoral head. We also performed sufficient bone grafting in the inner channels to promote or induce bone formation. The synergy between the support of the outer upper channel and sufficient bone grafting of the inner channel makes up for the contradiction that bone grafting and support weaken one another. Zhou et al. [30] conducted a biomechanical study and found that partially debriding the necrotic area appears to be a better choice for avoiding the collapse of the femoral head. Hence, we did not completely remove the dead bone. The only disadvantage of our technique may be that there is greater radioactive exposure with it than with the Phemister technique.

There are several limitations. First, the sample size was small and the follow-up time short. Large sample and long-term follow-up results are thus needed. Second, risk factors that may lead to surgical failure deserve further analysis.

\section{Conclusion}

SDBS is an effective method for treating early-stage ONFH. It has the advantages of being minimally invasive and offers rapid postoperative recovery, no donor complications, and good recovery of hip function. It represents a new method for treating early-stage ONFH.

\section{Abbreviations \\ ONFH: Osteonecrosis of the femoral head; SDBS: Single approach to double- channel core decompression and bone grafting with structural bone support; ARCO: Association Research Circulation Osseous; FFA: Fresh-frozen allograft; DBM: Demineralized bone matrix; HHS: Harris hip score; PACS: Picture archiving and communication system; THA: Total hip arthroplasty; HA: Hydroxyapatite}

\section{Acknowledgements}

We thank Nancy Schatken BS, MT (ASCP), from Liwen Bianji, Edanz Group China (www.liwenbianji.cn/ac), for editing the English text of a draft of this manuscript.

\section{Authors' contributions}

JAY collected the data and wrote articles; XZG invented the single approach to double-channel core decompression and bone grafting with structural bone support (SDBS) and did the surgery; RDW, BL, QS, WYL, JC, and YNL were responsible for the literature review. The authors read and approved the final manuscript. This article conforms to the journal style.

\section{Funding}

No.

\section{Availability of data and materials}

All data and materials used to support the findings of this study are included within the article.

\section{Ethics approval and consent to participate}

All procedures performed in studies involving human participants were in accordance with the ethical standards of the World Medical Association Declaration of Helsinki Ethical Principles for Medical Research Involving Human Subjects. The Ethics Committee of Aviation General Hospital approved this study. All patients agreed to participate in it.

\section{Consent for publication}

All authors agree to publish "Single approach to double-channel core decompression and bone grafting with structural bone support for treating early-stage osteonecrosis of the femoral head" in the Journal of Orthopaedic Surgery and Research. 


\section{Competing interests}

We declare that we do not have any commercial or associative interest that represents a conflict of interest in connection with the work submitted.

Received: 11 December 2019 Accepted: 20 May 2020

Published online: 29 May 2020

\section{References}

1. Chen X, Tan X, Gao S, Zhang X, Li J, Liu Y. Sartorius muscle-pedicle bone graft for osteonecrosis of the femoral head. Int Orthop. 2016;40:1417-25.

2. Mont MA, Zywiel MG, Marker DR, McGrath MS, Delanois RE. The natural history of untreated asymptomatic osteonecrosis of the femoral head: a systematic literature review. J Bone Joint Surg Am. 2010;92:2165-70.

3. Kang JS, Moon KH, Kwon DG, Shin BK, Woo MS. The natural history of asymptomatic osteonecrosis of the femoral head. Int Orthop. 2013;37:379-84.

4. Sun W, Li Z, Gao F, Shi Z, Zhang Q, Guo W. Recombinant human bone morphogenetic protein-2 in debridement and impacted bone graft for the treatment of femoral head osteonecrosis. PLoS One. 2014;9:e100424.

5. Kianmehr N, Bidari A, Mofidi M, Bahar N. Silent osteonecrosis of the femoral head following high-dose corticosteroids in patients with systemic rheumatic diseases. Med J Islam Repub Iran. 2015;29:259.

6. Kubo Y, Motomura G, Ikemura S, Sonoda K, Yamamoto T, Nakashima Y. Effect of collapse on the deformity of the femoral head-neck junction in osteonecrosis of the femoral head. Arch Orthop Trauma Surg. 2017;137:933-8.

7. Lieberman JR, Engstrom SM, Meneghini RM, SooHoo NF. Which factors influence preservation of the osteonecrotic femoral head. Clin Orthop Relat Res. 2012;470:525-34.

8. Ma J, Sun W, Gao F, Guo W, Wang Y, Li Z. Porous tantalum implant in treating osteonecrosis of the femoral head: Still a Viable Option. Sci Rep. 2016;6:28227.

9. PHEMISTER DB. Treatment of the necrotic head of the femur in adults. J Bone Joint Surg. 1949;Am 31A:55-66.

10. Tomaru Y, Yoshioka T, Sugaya H, Aoto K, Wada H, Akaogi H, Yamazaki M, Mishima $\mathrm{H}$. Hip preserving surgery with concentrated autologous bone marrow aspirate transplantation for the treatment of asymptomatic osteonecrosis of the femoral head: retrospective review of clinical and radiological outcomes at 6 years postoperatively. BMC Musculoskelet Disord. 2017;18:292

11. Sultan AA, Khlopas A, Surace P, Samuel LT, Faour M, Sodhi N, Krebs VE, Stearns KL, Molloy RM, Mont MA. The use of non-vascularized bone grafts to treat osteonecrosis of the femoral head: indications, techniques, and outcomes. Int Orthop. 2019;43:1315-20.

12. Zhang C, Zeng B, Xu Z, Sui S, Song W, Jin D, Shi H, Wang K. Treatment of osteonecrosis of femoral head with free vascularized fibula grafting. Zhongguo Xiu Fu Chong Jian Wai Ke Za Zhi. 2004;18:367-9.

13. Wei BF, Ge XH. Treatment of osteonecrosis of the femoral head with core decompression and bone grafting. Hip Int. 2011;21:206-10.

14. Hsu JE, Wihbey T, Shah RP, Garino JP, Lee GC. Prophylactic decompression and bone grafting for small asymptomatic osteonecrotic lesions of the femoral head. Hip Int. 2011:21:672-7.

15. Keizer SB, Kock NB, Dijkstra PD, Taminiau AH, Nelissen RG. Treatment of avascular necrosis of the hip by a non-vascularised cortical graft. J Bone Joint Surg (Br). 2006;88:460-6.

16. Mont MA, Carbone JJ, Fairbank AC. Core decompression versus nonoperative management for osteonecrosis of the hip. Clin Orthop Relat Res. 1996:169-78.

17. Xiong Y, Ren C, Zhang B, Yang H, Lang Y, Min L, Zhang W, Pei F, Yan Y, Li $\mathrm{H}$, Mo A, Tu C, Duan H. Analyzing the behavior of a porous nanohydroxyapatite/polyamide 66 (n-HA/PA66) composite for healing of bone defects. Int J Nanomedicine. 2014;9:485-94.

18. Hu J, Ou Y, Zhu Y, Luo W, Zhao Z, Du X, Li J. Effectiveness of nanohydroxyapatite/polyamide-66 Cage in interbody fusion for degenerative lumbar scoliosis. Zhongguo Xiu Fu Chong Jian Wai Ke Za Zhi. 2019;33:287-95.

19. Shuai C, Gao C, Feng P, Peng S, Wen X. Grain growth associates mechanical properties in nano-hydroxyapatite bone scaffolds. J Nanosci Nanotechnol. 2013;13:5340-5

20. Deng QX, Ou YS, Zhu Y, Zhao ZH, Liu B, Huang Q, Du X, Jiang DM. Clinical outcomes of two types of cages used in transforaminal lumbar interbody fusion for the treatment of degenerative lumbar diseases: n-HA/PA66 cages versus PEEK cages. J Mater Sci Mater Med. 2016;27:102.
21. Yang P, Bian C, Huang X, Shi A, Wang C, Wang K. Core decompression in combination with nano-hydroxyapatite/polyamide 66 rod for the treatment of osteonecrosis of the femoral head. Arch Orthop Trauma Surg. 2014;134: 103-12.

22. Martin GJ Jr, Haid RW Jr, MacMillan M, Rodts GE Jr, Berkman R. Anterior cervical discectomy with freeze-dried fibula allograft. Overview of 317 cases and literature review. Spine (Phila Pa 1976). 24:852-8 discussion 858-859.

23. Caplanis N, Lee MB, Zimmerman GJ, Selvig KA, Wikesjö UM. Effect of allogeneic freeze-dried demineralized bone matrix on regeneration of alveolar bone and periodontal attachment in dogs. J Clin Periodontol. 1998; 25:801-6.

24. Stevenson S. Enhancement of fracture healing with autogenous and allogeneic bone grafts. Clin Orthop Relat Res. 1998:S239-46.

25. Wang C, Peng J, Lu S. Summary of the various treatments for osteonecrosis of the femoral head by mechanism: a review. Exp Ther Med. 2014:8:700-6.

26. Pierce TP, Elmallah RK, Jauregui JJ, Poola S, Mont MA, Delanois RE. A current review of non-vascularized bone grafting in osteonecrosis of the femoral head. Curr Rev Musculoskelet Med. 2015;8:240-5.

27. Wu CT, Yen SH, Lin PC, Wang JW. Long-term outcomes of Phemister bone grafting for patients with non-traumatic osteonecrosis of the femoral head. Int Orthop. 2019;43:579-87.

28. Mont MA, Cherian JJ, Sierra RJ, Jones LC, Lieberman JR. Nontraumatic osteonecrosis of the femoral head: where do we stand today? A ten-year update. J Bone Joint Surg Am. 2015;97:1604-27.

29. Guo X, Dou B, Zhou Y, Li Y. Surgical treatment of necrosis of the femoral head in early stages with core depression and allo-fibular grafting. Zhongguo Xiu Fu Chong Jian Wai Ke Za Zhi. 2005;19:697-9.

30. Zhou G, Zhang Y, Zeng L, He W, Pang Z, Chen X, Xu Y, Stephen LS, Chen L. Should thorough debridement be used in fibular allograft with impaction bone grafting to treat femoral head necrosis: a biomechanical evaluation. BMC Musculoskelet Disord. 2015:16:140.

\section{Publisher's Note}

Springer Nature remains neutral with regard to jurisdictional claims in published maps and institutional affiliations.
Ready to submit your research? Choose BMC and benefit from:

- fast, convenient online submission

- thorough peer review by experienced researchers in your field

- rapid publication on acceptance

- support for research data, including large and complex data types

- gold Open Access which fosters wider collaboration and increased citations

- maximum visibility for your research: over $100 \mathrm{M}$ website views per year

At $\mathrm{BMC}$, research is always in progress.

Learn more biomedcentral.com/submissions 